\title{
The Five Ws of the
} Water-Energy-Food Nexus: A Reflexive Approach to Enable the Production of Actionable Knowledge

OPEN ACCESS

Edited by:

Bassel Daher,

Texas A\&M Energy Institute,

United States

Reviewed by:

Antje Bruns,

University of Trier, Germany

K. S. Kasiviswanathan,

Indian Institute of Technology

Roorkee, India

*Correspondence:

Darin Wahl

darin.wah/@/ucsus.lu.se

Specialty section This article was submitted to

Water and Human Systems,

a section of the journal

Frontiers in Water

Received: 23 June 2021 Accepted: 02 September 2021 Published: 29 September 2021

Citation:

Dalla Fontana M, Wahl $D$ Moreira FdA, Offermans A, Ness B, Malheiros TF and Di Giulio GM (2021)

The Five Ws of the

Water-Energy-Food Nexus: A

Reflexive Approach to Enable the Production of Actionable Knowledge.

Front. Water 3:729722.

doi: 10.3389/frwa.2021.729722

\author{
Michele Dalla Fontana ${ }^{1}$, Darin Wahl ${ }^{2 *}$, Fabiano de Araujo Moreira ${ }^{1}$, Astrid Offermans ${ }^{3}$, \\ Barry Ness ${ }^{2,4}$, Tadeu Fabrício Malheiros ${ }^{5}$ and Gabriela Marques Di Giulio ${ }^{1}$ \\ ${ }^{1}$ School of Public Health-Department of Environmental Health, University of São Paulo (USP), São Paulo, Brazil, ${ }^{2}$ Lund \\ University Centre for Sustainability Studies (LUCSUS), Lund, Sweden, ${ }^{3}$ Maastricht Sustainability Institute, Maastricht \\ University, Maastricht, Netherlands, ${ }^{4}$ Centre for Innovation Research, Lund University (CIRCLE), Lund, Sweden, ${ }^{5}$ São Carlos \\ School of Engineering-Department of Hydraulics and Sanitation Engineering (SHS-EESC), University of São Paulo (USP), \\ São Paulo, Brazil
}

The water-energy-food nexus is now a popular approach in the sustainability field. However, whereas the nexus calls for more holistic, inter- and transdisciplinary approaches, the research produced over the past decade has been fragmented and specialized. Furthermore, there is still a gap between the nexus as a descriptive and analytical concept and its operationalization. Nexus research needs a shift from "thinking" to "action," which we understand as the production of actionable knowledge. This paper delves into the literature and presents five "W" questions as an iterative heuristic for the nexus concept to encourage reflexivity and inter-and transdisciplinary dialogue, while aiming at the production of actionable knowledge. We draw on the literature to discuss the five "W" questions of the nexus, namely: (i) Why, in which we explore the purpose of nexus research for actionable knowledge; (ii) What, in which we explore the material aspect of the nexus and the interactions between water, energy and food systems; (iii) Where, in which we discuss issues of scale, interactions between scales, and the geographical context of the nexus; (iv) When, in which we consider temporal dimensions of nexus research with a particular emphasis on intergenerational trade-offs, and (v) Who, which focuses on nexus stakeholders and the importance of understanding issues of justice and equity. Finally, we discuss the connections and dependencies between the five Ws, reinforcing the importance for researchers to reflect on their decision-making and engage in inter- and transdisciplinary debate to enable nexus action.

Keywords: interdisciplinary, transdisciplinary, sustainability, collaboration, systems thinking

\section{INTRODUCTION}

The water-energy-food (WEF) nexus has been associated with a multitude of terms since its advent. It has been presented as a concept, a tool, a perspective, an approach, a framework, or a buzzword (Biggs et al., 2015; Cairns and Krzywoszynska, 2016; Rasul and Sharma, 2016; Al-Saidi and Elagib, 2017; Simpson and Jewitt, 2019b). On the one hand, this makes the nexus popular across academic fields; however, on the other hand, it remains a vague and elusive concept, rarely put into practice, and halfway between "novelty and nullity" (Allouche et al., 2014; Wichelns, 2017). 
The general definition of the nexus, as a conceptual and analytical approach to integrated resource management focused on the synergies and trade-offs between water, energy and food systems, can be too abstract to have practical implications, and too broad to be addressed in its entirety. The use of WEF nexus methods to systematically evaluate water, energy, and food interlinkages, or to support the development of policies, has therefore been limited. Nexus methods frequently fall short of comprehensively capturing connections and interlinkages, and only a small number of documented methods combine diverse disciplines (Albrecht et al., 2018). This is due to many factors, including the complex (Dargin et al., 2019) and dynamic (Zhang and Vesselinov, 2017) nature of nexus systems, which is challenging to capture in a single method or tool (see Daher et al., 2017). It is therefore not by chance that the research produced over the past decade on the nexus has been fragmented and specialized, being juxtaposed with topics as diverse as human urine fertilizer (Medeiros et al., 2020) and the geographies of children, youth, and families (Walker, 2020).

Review papers on the nexus have been abundant over recent years (Leck et al., 2015; Endo et al., 2017; Albrecht et al., 2018; Simpson and Jewitt, 2019b), and Wiegleb and Bruns (2018) reveal that there are two distinct formations of the scientific nexus discourse (i.e., a dominant technical discourse and growing social approaches). While we recognize the need of defining boundaries to perform meaningful research, in this paper, we contribute to the literature that calls for more inter- and transdisciplinary approaches (e.g., Biggs et al., 2015; Rasul, 2016; Howarth and Monasterolo, 2017; Kurian, 2017). Furthermore, we argue that future nexus research should aim at achieving the security and sustainability goals with which the concept has now entangled (Bleischwitz et al., 2018; Liu et al., 2018; Vanham et al., 2019). For this, we agree with Simpson and Jewitt (2019a) that a shift in nexus research from "thinking" to "action" is necessary, which we understand as the production of actionable knowledge.

Therefore, this paper addresses five "W" questions as an iterative heuristic for the nexus concept to encourage reflexivity and inter- and transdisciplinary dialogue, while promoting the production of actionable knowledge. In the following sections, we draw on the literature to discuss the five Ws of the nexus, namely: (i) Why, in which we explore the purpose of nexus research for actionable knowledge; (ii) What, in which we explore the material aspect of the nexus and the interactions between water, energym and food systems; (iii) Where, in which we discuss issues of scale, interactions between scales, and the geographical context of the nexus; (iv) When, in which we consider temporal dimensions (past, future orientation) of nexus research with a particular emphasis on intergenerational trade-offs, and (v) Who, which focuses on nexus stakeholders and the importance of understanding issues of justice and equity. We conclude the paper by highlighting the connections and dependencies between the five Ws, stressing the importance for researchers to reflect on their decision-making and engage in inter- and transdisciplinary dialogues.

\section{WHY?}

In the last decade, the nexus has served different agendas, and the research carries with it a normative stance accepting that water, energy, and food systems are interdependent and that they should be managed as such, for the long-term security of these systems. The resource security perspective can also largely be assumed to be aligned with sustainability and sustainable development, in that the real world implications are inseparable, i.e., we cannot achieve the long-term security of WEF resources globally without at the same time achieving sustainability goals and vice versa (Bleischwitz et al., 2018; Liu et al., 2018; Vanham et al., 2019). Therefore, when engaging in WEF research, especially research that is solution oriented, it is important to understand why this research is relevant within this normative position. The why questions aim to interrogate the purpose of nexus research for actionable knowledge, which requires diving into specifics. To achieve security and sustainability of WEF resources, in other words, it is necessary to align research with purpose.

Although it often follows market logic, nexus research is not only concerned with win-win solutions for the resource systems and business interests, but it is also motivated by the urge to meet the needs of people whose health and livelihoods are dependent on these systems (Biggs et al., 2015; Cairns and Krzywoszynska, 2016). Therefore, nexus interventions should consider what purpose they are going to serve, whose interests are going to be prioritized and whose voices will go unheard. Many studies are motivated by the goal of increasing efficiency of resource use and supply, and they do so through the development of technical solutions (Sanjuan-Delmás et al., 2018; Yuan et al., 2021). However, within these studies there are far fewer that can be said to be actionable, as many do not consider the socio-politicaleconomic intricacies of implementation (Villarroel Walker et al., 2017). Actionable knowledge within technical or efficiency solutions must include an understanding of administrative, cultural, or economic barriers and even present strategies to overcome them (Tengö and Andersson, 2021).

Intervention research should reflect on whether the solution reinforces the status quo and hinders substantial and systemic changes to happen; or if the solution provides an alternative to the prevalent paradigms. In these cases, system understanding can be used to determine leverage points for change (Meadows, 1999) along with potential for purposeful coordination of governance structures across levels and sectors to enable transformational change (Pahl-Wostl, 2019).

Different issues contribute, to varying degrees, to formulate the reasons behind nexus research and to legitimize the efforts to develop nexus solutions. It is therefore not possible, nor desirable, to dissociate the why of the nexus from: the specific interactions that we are focusing on (what), the geographical context and priorities that vary from place to place (where), the temporal perspective that can favor short- or long-term results (when), and the producers and beneficiaries of the actionable knowledge (who). Moreover, in considering the why, research for actionable knowledge in the nexus becomes politicized, as interventions in resource systems are inherently political (Turnhout et al., 2020). Key concerns for the nexus in this context are access and power, 
with one often determining the other (Allouche et al., 2015; Middleton et al., 2015). To develop actionable solutions then, it may be necessary to understand across scales and at local levels what system elements hold unequal access in place, and where practices have adapted to variable WEF access and availability (Giatti et al., 2019).

\section{WHAT?}

Concentrating on the nexus means a focus on system interactions. The focus is not only on a single object, but also on discovering what are the connections between the respective systems. Interactions can have positive and constructive characteristics, i.e., synergies, or can result in unexpected and negative imbalances, i.e., trade-offs. How these interactions manifest is not always straight-forward, and once we start breaking down the WEF nexus into more detail, we realize that we are actually dealing with different nexuses. It is difficult to understand the entirety of the nexus in a single case assessment, so systems boundaries must be set (Garcia and You, 2016). Therefore, two of the first questions we ask are (i) what kind of water, energy, and food are being considered, and (ii) what specific interactions are we concentrating on?

\section{What Water, What Energy, What Food?}

Before mapping, identifying, assessing and quantifying interactions, it is important to understand that not all water, energy and food elements are the same. It is important to gain a solid understanding of the respective systems, by identifying interactions and impacts of different quantity and quality.

- What Water? Water is available from two coupled natural sources, the blue and green water systems, and one human source, gray water. Each water source has different and important implications for withdrawal, storage, transport, or pumping (Falkenmark et al., 2004; Hoekstra et al., 2011). Depending on the kind of water that enters or leaves the food and energy sectors, nexus interactions can result in different kinds of impacts (both in terms of quantity and quality), which may require different considerations and solutions.

- What Energy? Energy can also greatly vary in terms of kind (e.g., electrical energy, thermal energy) and source (e.g., fossil fuels, renewable sources, nuclear, etc.). This has direct implications on water requirements in both the production process and the use-phase. For example, far more water per MWh energy generated is necessary for biodiesel than for solar panels or wind turbines (D'Odorico et al., 2018). Furthermore, the different sources of energy, as well as energy inputs in the water and food sectors (e.g., for pumping, irrigating and transport) result in more or less GHG emissions associated with those sectors.

- What Food? Whether we are dealing with fruit, vegetable, meat, or grain, from the farm to the consumer to waste disposal, the WEF aspect/s of the value chain in focus shift depending on the kind of food and its level of processing. This is because the interactions of food with water and energy change dramatically along the food value chain. A classic example is coffee, where some water is used in the roasting process and for preparing your cup of coffee, but where the majority of water (almost 96\%) goes into growing the coffee shrub in the form of green water (Mekonnen and Hoekstra, 2010). However, the amount of water and energy "from farm to fork" varies greatly according to the product, farming practices, location, techniques and technologies in the value chain, transportation and other variables, and all are very difficult to track with precision.

\section{What Interactions?}

Literature on the nexus is heterogeneous and different scholars have focused on different and specific interactions. The goal of this section is not to offer a complete inventory of all possible interactions, but instead to illustrate different potential nexuses, and researchers should identify the nexus that is most relevant to their case. Figure 1 provides a visual representation of some of these interactions between water, energy and food value chains that can be found in the literature and that are addressed in the following paragraphs.

Biofuels production is an often used textbook example in which water-energy-food interactions plainly unfold both as synergies and trade-offs (D'Odorico et al., 2018). Crops (food) are grown for energy production purposes, becoming a plausible alternative to fossil fuel in the global energy matrix. However, this also results in competition in the use of crops and water for both energy and food production (trade-off) (Rulli et al., 2016). Hydroelectric dams is another often cited case to illustrate the nexus, in which water is instrumental to meet increasing energy needs (synergy) while affects biodiversity, land use, agricultural land and fisheries (trade-offs) (Winemiller et al., 2016; de Queiroz et al., 2019; Paim et al., 2019).

In addition to these well-known examples, many other nexuses are embedded along water, energy and food value chains. At all stages of the food value chain there are water-energy-food interactions, from the primary production of food (including crop, livestock, and fish production) to processing and storage, distribution and retail, preparation and cooking, and food waste (FAO, 2013). Among others, aspects to consider include differences in water and energy demand between products from crop and animal origin and differences in water demand based on the geographical characteristics of production (with fluctuations in e.g., temperatures and evaporation). For example, in general the production stage of food accounts for about $20 \%$ of final energy consumption, processing and distribution is just over $40 \%$, and the remaining is represented by retail, preparation and cooking activities (FAO, 2013).

Most research focuses on one or two stages in the supply chain. For water to food, for example, FAO has a long tradition of studies looking into the interactions between water and primary production of food, whether this is water used to irrigate crops, consumed to rear animals or used in aquaculture (e.g., Best et al., 2000; FAO, 2013). Kirby and colleagues delve into the different uses of water in food processing (e.g., preparation of products, cleaning and washing activities, air conditioning and humidity control systems) (Kirby et al., 2003). While water consumption in transportation 


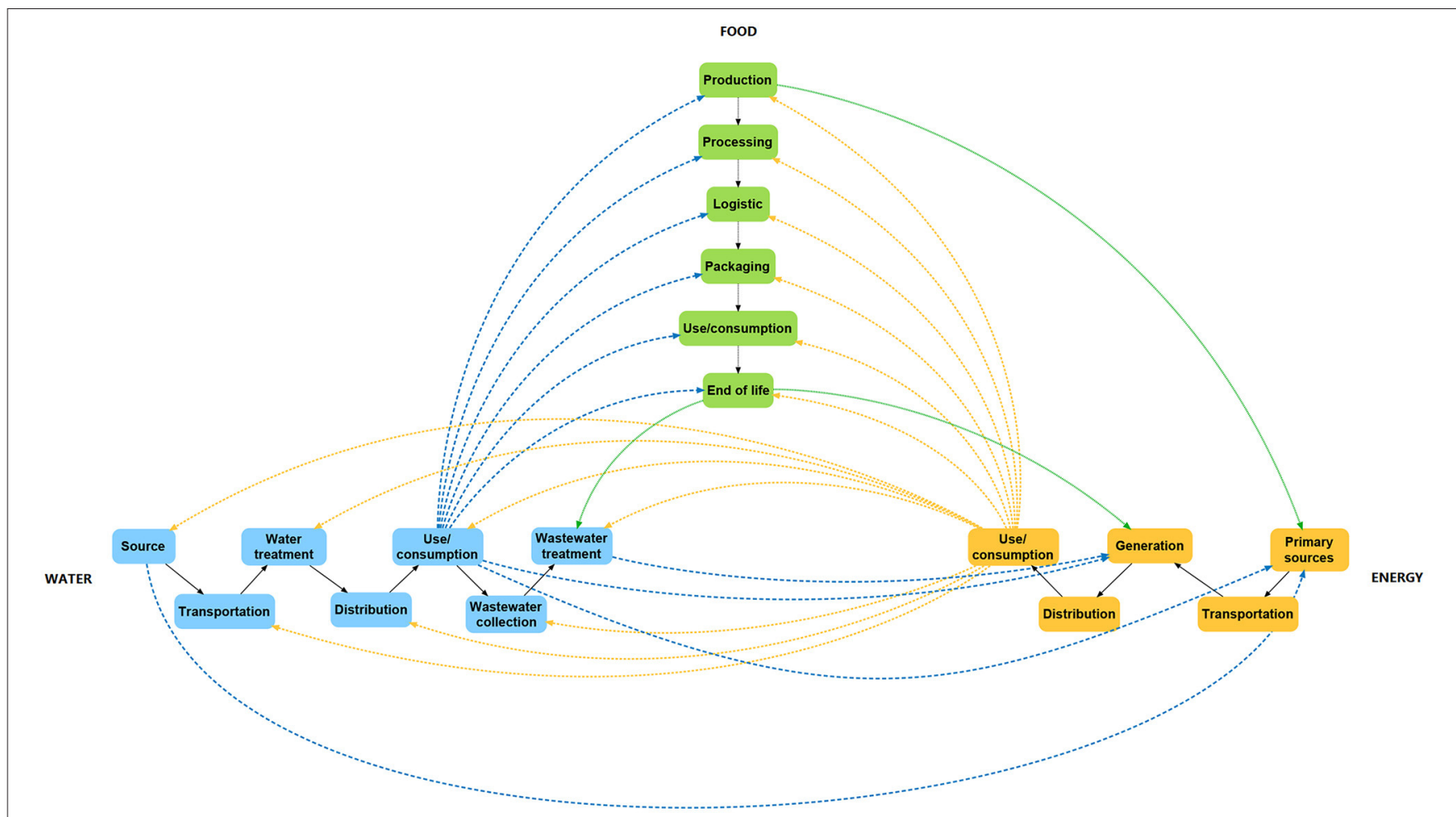

FIGURE 1 | Interactions between water, energy, and food value chains.

and distribution operations is generally considered to be negligible, other interactions may take place in logistics and packaging (Stoessel et al., 2012; Petljak et al., 2018). Furthermore, some scholars focus on final use/consumption practices (e.g., cooking) and recognize them as important aspects of the nexus (Wa'el et al., 2017; Mguni et al., 2020).

In a similar way, energy is used in each stage of the food value chain, therefore characterizing energy-food interactions. In this regard, the European Commission Joint Research Center (JRC) provides a detailed breakdown of the food value chain to estimate the energy embedded in a sample basket of products (Monforti et al., 2015).

The inclusion of food waste as a particular focus point in the food supply chain is not common, but relevant given its position in the intricate web of the nexus. Kibler et al. (2018) give a very thorough overview of the interconnections between water, food and energy of various food waste management options: such as waste prevention, landfilling, composting, anaerobic digestion, and incineration.

With regard to water-energy interactions, the most relevant water-to-energy interactions coincide with primary energy production activities and with cooling processes in power plants (IEA, 2016). Examples of water-to-energy interactions occur, for instance, in mining activities, growing biomass crops, hydropower generation, micro hydropower systems, and steam and cooling water in thermal plants (Hamiche et al., 2016). Other water-related interactions along the energy value chain (i.e., transmission, distribution, consumption) are less relevant due to the small volume of water involved.

On the other hand, if you look at energy-to-water interactions, energy is used in all the phases of the water value chain, including wastewater collection and treatment. The global water sector consumes energy mainly in the form of electricity that is primarily used for extraction of groundwater and surface water, followed by wastewater collection and treatment. Electricity is also applied to distribute water to the final consumer and, to a lesser extent, in desalination processes, freshwater treatment, inter-basin transfers, and water reuse. Other nexustype interactions are found, for example, as thermal energy used in diesel pumps for extracting groundwater for agricultural purposes (IEA, 2016). In addition, other scholars identify waterenergy interactions at the final consumer/user stage, such as energy for hot water heating, showering, bathing, hand wash basin tap use, laundry, dishwashing, or cooking (Kenway et al., 2011; Engström et al., 2017; Wa'el et al., 2017).

\section{WHERE?}

Where is the nexus that we are trying to research? The interactions that we have seen in the previous section can be part of a very large and extremely complex system that can span spatial levels. Setting system boundaries is a crucial element in order to limit research to a level and amount that is feasible to address, yet comprehensive enough to capture important 
WEF flows and interactions, as well as proposed actions and their impacts. Moreover, it is important to recognize which geographical context (or contexts) the nexus under research is taking place, since in different places there are different stakeholders (see who section), with different needs, interests, and values (see why section). In recent years, there has been a shift in focus in nexus research from global-to-local (Artioli et al., 2017; Newell et al., 2019). Newell et al. (2019), for example, show that there is an emerging academic community focusing on the urban aspects of the nexus. Urban systems, however, are largely dependent on external inputs of resources and therewith- generate WEF impacts that go beyond the city's physical boundaries. The complexity of the WEF nexus forces research to set manageable system boundaries that cover relevant spatial scales and the key points of WEF-entanglement (Garcia and You, 2016; Wahl et al., 2021).

\section{Interactions Across Levels}

A characteristic of the WEF nexus is that the three systems will likely span different spatial levels (Bijl et al., 2018). This is because nexus resource systems are embedded in larger socialecological and technical systems, which both overlap and are interdependent in various ways, making boundaries between scales, and sectors unclear (Lant et al., 2019). Therefore, choices must be made to select relevant aspects of the nexus in space, but also in sector and approach. However, determining what is relevant is not immediately clear. Beyond the physical aspects of the nexus there are governance, climate, cultural contexts that are often also different for each nexus resource. For example, governance of the nexus is fraught with scalar challenges in which actors and actions, operating procedures, and rules and norms are often on miss-matched scales and levels (Pahl-Wostl, 2019). Nevertheless, navigating these layers of "where is the nexus?" is essential, especially if the aim is to develop actionable knowledge.

In many cases the concept of the nexus is applied on the global level; however, for the sake of research, the global system can be subdivided in different subsystems, acknowledging that they are interconnected and that what happens in one subsystem can have effects on other subsystems. Garcia and You (2016, p. 57) recommend to at minimum integrate the focal system with "affecting and affected" systems. In other words, the research boundaries can be set at the levels of direct influence on or from the focal system. For example, a study of Delhi's WEF nexus found that more than $76 \%$ of nexus resources were produced outside of the city, though still dominantly in the country (Ramaswami et al., 2017). Yet, nexus systems are also often highly tele-coupled, in that due to globally interconnected systems of economics and trade, direct connections exist over large distances (Liu et al., 2013). Dalin et al. (2017) show that about $11 \%$ of non-renewable groundwater use for irrigation is embedded in international food trade, and that the vast majority of the world's population lives in countries that import almost all their staple crops from countries that are depleting groundwater sources to grow these crops.

Adding a solutions orientation changes the layers of "where is the nexus." Solutions to problems may need to be implemented in a different location from where the problems are identified, and impacts from such implementations may occur beyond the identified problem area (King and Carbajales-Dale, 2016). The multi-scalar nature of the nexus along with its tele-coupled aspects, makes it very likely that locations of impact and influence are beyond the local area. These beyond-local interactions are crucial to understand for developing meaningful sustainable solutions, which are meant to be synergistic with other efforts, whether they are local or not (Engström et al., 2018). Therefore, it may be useful to start at an intervention, and build the system understanding from there including any systems of influence or potential impact (Wahl et al., 2021).

\section{Different Nexuses for Different Geographies}

The place and context-based nature of nexus systems make the transfer of solutions to other contexts unsure. Socio-cultural, political, and/or economic differences (Taniguchi et al., 2019) need to be considered as well as the social-ecological fit of solutions transferred to new locations. Social-ecological fit aims to develop synergistically beneficial outcomes for society and the environment through aligning governance and formal and informal institutions with the dynamics of natural or resource systems (Enqvist et al., 2020). This, among other aspects, requires an understanding of local priorities and the potential disciplinary, regulatory frameworks, barriers and obstacles to cross-sectoral coordination (Kurian, 2017).

Wiegleb and Bruns (2018) point out that while the nexus is applied mainly in specific regions of the Global South, it is largely shaped by western knowledge. However, it must be recognized that in many places on the planet, basic access to water, energy, and food is not guaranteed to the entire population. Thus, while it may be understandable that the nexus is mainly used to ensure (green or circular) economic growth in developed countries, in many developing countries the focus may be better directed toward what Raworth (2017) calls the social foundation of the economy (see also Schlör et al., 2018). In this case, nexus solutions development can be first of all oriented at meeting basic needs and guarantee access to water, energy and food for all (see who section).

\section{WHEN?}

The time scale of WEF interactions is tied to the spatial scale, in that as one changes, the other changes as well. Garcia and You (2016) pointed out how, at the household level, the purchase and consumption of water, energy, and food can occur on the order of hours or days. On the other hand, the supply chains of such resources can operate at a regional or even global level on the basis of years and or decades.

Ignoring the temporal dimension of the nexus may lead to short-term solutions that aggregate into long-term problems (Cash et al., 2006). Although the question of the time scale is mentioned several times in the literature, there are not many studies that explore this issue in depth. Despite this, we believe that asking the question of "when?" is an important aspect to 
consider to overcome the mainly descriptive character of existing studies and make progress in nexus research.

Scientific research regarding the nexus has been largely driven by a narrative of scarcity. Papers often start providing evidence on how the demand for water, energy, and food will increase dramatically in the coming decades under the pressure of a growing world population, increasing standard of living, and a steady process of urbanization; and how such resources will become increasingly scarce under different climate scenarios. A large part of the research is therefore driven by referring to future trends, to understand and assess synergies and tradeoffs between water, energy and food systems under uncertain scenarios via quantitative measurements, computer simulation modeling and prediction (Wiegleb and Bruns, 2018; Zhu et al., 2020). Econometrics, economic models and benefit cost analysis are also often used to forecast how different factors can affect complex systems and to indicate the best allocation of resources (Endo et al., 2015).

According to Liu et al. (2015), the integration between temporal scales (e.g., short-term fluctuations in earth systems processes with long-term projections) can greatly contribute to improve research results. Whereas, short term studies can capture immediate changes in systems behaviors, long-term studies are necessary to understand phenomena (e.g., cumulative effects and feedback mechanisms) that cannot be seen over shorter terms. The authors further argue that by paying attention to the historical temporal scale, it is also possible to "reveal legacy effects of prior human-nature couplings" (Liu et al., 2015, p. 3), meaning that you can better explain current systems behavior by looking at what happened in the past.

We can find a similar trend in nexus research: (i) one can study the interactions between water, energy, and food by looking at past events to explain the present; (ii) one can look at current interactions to understand how to obtain certain outcomes in the short term; (iii) or one can go so far as to imagine what the consequences of certain initiatives might be in the long term. While the first of these possibilities has been little explored in nexus research (see for exceptions Guillaume et al., 2015; Pellegrini and Fernández, 2018), studies that look at how to plan for the future (whether near or distant) have certainly been more popular. This is why you can often find studies that combine the concept of the nexus with systems dynamic and agent-based models, as they create virtual representations of the world to test different possible outcomes under different scenarios (Liu et al., 2015; Magliocca, 2020).

In their literature review on the nexus at urban scale, Newell et al. (2019) show how there are studies that work on time horizons of just 1 or 2 years, and in doing so they are unable to capture slow transformations or decadal climate dynamics, while others model multiple decades. While the integration of shortand long-term research is preferable, some researchers point out how difficult it is to find a balance between temporal dimensions and how many models fail to capture long-term dynamics (that are often uncertain in themselves), thus not being able to support decision-making on sustainability issues (Allain et al., 2018). These difficulties are even more pronounced when trying to model nexus interactions, as trade-offs between water, energy, and food tend to occur over very long time scales (Magliocca, 2020). For example, Ericksen (2008, p. 243) raises the question of how "increased agricultural productivity today may be at the cost of sufficient water availability in the future," arguing that many trade-offs involving ecosystem services are often between short-term gains and long-term costs.

This contraposition between short- and long-term solutions raises issues of intergenerational equity. While some concern about justice and equity between individuals and communities is somehow discussed in the nexus literature (see who section), the issue of intergenerational equity is rarely addressed explicitly. Nevertheless, this is a question that needs to be asked while doing research and looking for solutions. Do the research and solutions that are developed around the nexus meet immediate people's needs? And how does this affect or undermine the ability to meet the needs of future generations? Or to put it differently, how is the concern about facing increasing resource demand in the coming decades affecting the way we ensure access to resources for the current generations? (Ciegis et al., 2009; Hake et al., 2016; Schlör et al., 2018).

Resource scarcity is not the only concern, but also the consequences of the actions taken to make up for that scarcity can be problematic. This is the reason why, for example, in a context of local water scarcity, the choice and implementation of water supply alternatives such as desalination, inter-basin water transfers, increased treatment and water re-use should also be evaluated in light of longterm energy implications (Khan et al., 2018). On top of that, another question emerges: how do the solutions we implement today determine the solutions we can implement in the future? The implementation of certain solutions can in fact create path dependence, intended as "the dependence of future societal decision processes and/or socio-ecological outcomes on those that have occurred in the past" (Preston, 2013, p. 719). Hoff (2011), in his background paper for the Bonn 2011 Nexus conference, was presenting the nexus as an approach that could help to avoid sunk costs that lock development into non-sustainable pathways. Thus, the nexus could help to develop and implement, for example, small scale, flexible, low-regrets, and decentralized measures increasing resilience to future shocks and crisis, rather than to primarily support and justify large, longlasting infrastructures and engineered-based solutions (de Bremond et al., 2014; Ernst and Preston, 2017; Dalla Fontana and Boas, 2019).

Nonetheless, the research largely proposes technological, technocratic and managerial solutions that do not touch on the diverse root causes of the problems (Wiegleb and Bruns, 2018), or focus on the implementation of large-scale and long-lasting interventions (e.g., dams construction for hydropower, land use changes for biofuels production, large-scale interbasin transfers) (Dalla Fontana et al., 2020).

\section{WHO?}

In order to improve credibility, salience, and legitimacy of actionable knowledge (Cash et al., 2003; Hansson and Polk, 2018; 
Wahl et al., 2021) it is important to understand who the actors involved in all the phases of the research are, including who drives the research, who is developing and implementing research and solutions, and who benefits most from the solutions and who is excluded and left behind.

\section{Who Drives the Nexus Discourse?}

The discourse around the nexus gained momentum under the influence of international business elites of the World Economic Forum community and international institutions (e.g., the World Bank, UN World Water Assessment Programme) calling for action to integrate water security to economic growth (Allouche et al., 2015; Cairns and Krzywoszynska, 2016). The business sector, represented by large transnational corporations, was interested in actions that could improve efficiency of resources and win-win outcomes, as a means to overcome barriers imposed by expected resource scarcity and to prepare for investment scenarios (Cairns and Krzywoszynska, 2016). The nexus then found its way into the policy arena (e.g., UN 2030 Agenda), and became an object of research for many academics across several disciplines (Artioli et al., 2017).

This dual path of action toward the nexus from the business and public policy perspectives was determined by the call for efficiency of resources, which represents a strongly marketoriented approach for the primary actors involved in nexus discourse (Williams et al., 2014). While the private sector foresaw investments so the market could adjust to resource scarcity, international organizations used market-oriented economic policy tools to address the compartmentalization of nexus elements (Allouche et al., 2015). The complex interconnections between the sectors of nexus elements is also a reflection of struggles between different interest groups, often revealing a political and economic power dynamic. Indeed, the nexus betokens political terrain, especially if actors seek for implementation of innovations in different areas and sectors (Williams et al., 2014), which leads to the question of: who is developing the solutions?

\section{Who Develops the Solutions and the Research?}

Nexus studies and actions mostly focus on resources efficiency and integration between the elements with a market-oriented approach, but in order to achieve the necessary transformation and operationalization, nexus thinking must also pervade the policy sector (Venghaus and Hake, 2018). National development plans, for instance, developed by ministries and authorities of water, agriculture, energy, environment, infrastructure, spatial planning, and so on, can be a place where to mainstream the nexus, with a cascading effect over local plans (Hoff and Kasparek, 2016). The implementation in policy and practice needs the engagement of institutions that mediate environmental outcomes in a multi-governance fashion. This includes the definition of clear roles of different sectors and actors involved, with their challenges and objectives (see why section), to identify which policy integration is effective and efficient (Venghaus and Hake, 2018).
Local stakeholders become more prominent in this concern, since local/municipal governments are deeply involved in the implementation of actions and policies related to nexus elements (Artioli et al., 2017). This way, it is fundamental to consider the inclusion of relevant stakeholders at all stages of nexus thinking, especially the ones who have the agency to translate information into policy and other actions and to implement the solutions (Wahl et al., 2021).

There is a call to change from a top-down to a bottom-up perspective in nexus thinking, and to rely on transdisciplinary approaches that make it possible for academic and nonacademic actors to engage in solutions-oriented research (Kurian, 2017). Involving stakeholders as active producers (rather than consumers) of knowledge may enhance the effectiveness of knowledge use (Hoolohan et al., 2018). To include stakeholders in the research process is advantageous because it reveals and influences pre-existing power dynamics in policy systems, allowing the nexus thinking to go beyond specific categories and simplifications that aggregate previous patterns of institutional blindness, inequality and exclusion (Bréthaut et al., 2019). Researchers have a prominent role in this integration to coproduce solution-oriented research, bringing multiple actors from differing disciplinary backgrounds together, in different platforms, and bearing in mind the power dynamics inherent in integrative processes (Bréthaut et al., 2019; Wahl et al., 2021).

\section{Who Benefits From the Solutions?}

Despite the utilization of the nexus approach by international institutions and corporations to overcome resource scarcity through technological investments and innovations, principles of justice and equity are often neglected (Allouche et al., 2015). Securing the access to resources for all and well-being of the poorest and most vulnerable populations must also be considered when doing research and working on nexus solutions (Bizikova et al., 2013; Covarrubias et al., 2019). If not, the benefits of applying the nexus might continue to reinforce the status quo, favoring the interests of well-established actors, whereas the poorest and weakest actors may benefit the least, still struggling to have guaranteed access to resources (Allouche et al., 2015). On the other hand, the interests and values of local communities can be pursued through the development of local business and improvements in small-scale technologies to ensure, for example water security for smallholder farmers (Allouche et al., 2015), and recognizing the value of local social practices (Giatti et al., 2019). Effective stakeholder participation in governance of the nexus is also fundamental to guarantee equitable allocation of resources (Sharma and Kumar, 2020).

One way to increase the chances that the solutions and knowledge benefit and not undermine less-established actors is to engage them in bottom-up processes of co-production of knowledge (Howarth and Monasterolo, 2016). Researchers are in a position to give credence to the importance of including actors from more fragile communities in the social learning process, considering aspects of ethics, vulnerability, risk, values, pluralities of points of views, diversity, and 
differences between people (Jasanoff, 2005; Bizikova et al., 2013; Covarrubias et al., 2019). Benefits can go beyond marketoriented logics and include, for example, gains from the learning process. Through social learning, the consideration of the interactions from society toward researchers and stakeholders and vice-versa can improve the collective dialogue throughout engagement processes in nexus discussions (Jasanoff, 2005; Urbinatti et al., 2020), mitigating a "nexus of exclusion" (Giatti et al., 2019). Then, the nexus becomes an important educational, conceptual, and political tool that goes beyond market-oriented logics, considering social and environmental justice issues, enhancing community-level empowerment (Urbinatti et al., 2020).

Researchers working on the nexus might want to consider society's needs through a critical perspective utilizing inter- and transdisciplinary approaches (Ghodsvali et al., 2019). Critical social sciences researchers have a key role to reveal power dynamics in knowledge co-production processes, to provide a space where all the actors involved share responsibilities, debate ideas, and negotiate solutions (Williams et al., 2014; Allouche et al., 2015). Nonetheless, researchers from all disciplines should reflect on who is driving the research, who is involved in the research and who is not, and who the research is for.

\section{DISCUSSION}

Interactions are not only significant within WEF systems, but also within the way we approach researching the nexus. By addressing the five Ws and acknowledging their interconnections further argue for taking inter- and transdisciplinary approaches. In doing so, the potential for research to be largely speculative or hard to implement can be reduced.

The five Ws and the connections between them ground the research in a local context, integrating the production of scientific knowledge with relevant local realities. Furthermore, an overall purpose of producing actionable knowledge places sustainability needs as a central focus. Therefore, research will revolve around real world problems that are both general and location-specific.

While there is no single way to initiate a research project, and without suggesting that one question is more important than the others, we can start by looking at why. Answering why questions means clarifying the reasons for doing nexus research for actionable knowledge. The process of going through the other four questions can help to better define purpose. Thus, identifying which specific interactions we are working with, recognizing and integrating the needs and capacities of different actors, and aligning the research with the most appropriate temporal scale and geographical context, provides elements that help to identify a clearer purpose for doing research on the nexus.

Considering what to research in the nexus and what interactions are most relevant helps to set research boundaries. What questions are often aimed at identifying the material aspects of the nexus, and in turn aid in identifying relevant stakeholders, the most relevant spatial scale, and how interactions unfold across different spatial scales, and the short- or long-term research/action potentials.
The who dimension also has strong repercussions through the Ws, as who focuses on the identification and inclusion of stakeholders. Questions of who foreground ideas of plurality, knowledge integration, and many aspects of legitimacy (Mitchell et al., 1997; Cash et al., 2003; Hoolohan et al., 2018). But these ideas must filter through the other Ws to create actionable WEF research. The who aspect is intended for WEF researchers to not just be aware of stakeholders and researchers in connected disciplines, but for networks to be built, for intentions and research applications to align, and to engage in dialogue with stakeholders that influences the shape and direction of inquiry (Daher et al., 2017; Hoolohan et al., 2018). Furthermore, we argue for integration of social temporal realities and the local social context, to further ground nexus research in the local socio-cultural attributes. This, along with the alignment between physical and temporal scale contribute to establishing the relevance and timeliness of nexus research. Figure 2 summarizes the interdependencies between the five Ws of nexus research as they were discussed in this section.

We do not intend to uncover all possibilities of connection between the Ws, yet emphasize that these connections are often dependencies, as with the nexus itself. The goal of this paper is to encourage WEF researchers to capture those dependencies by advancing an inter- and transdisciplinary dialogue to the development of actionable knowledge in nexus research. Referring to the two distinct nexus discourses identified by Wiegleb and Bruns (2018), we understand that, for example, research in the dominant technical discourse tends to answer mainly what questions, while researchers who advocate more social approaches delve more frequently into who and why questions. We recognize that specific academic disciplines are more inclined and equipped to address some issues than others. However, going over the five Ws questions and considering their interdependencies clarifies the necessity of bringing together different perspectives and expertise to grasp nexus problems that are often complex and varied in nature. The five Ws give users of the WEF concept a frame for integrating their work with the local context, and incorporating sustainability concerns around justice, equity, and access, through creating research that aims to be societally timely and relevant (i.e., salient), scientifically credible, and seen as legitimate to stakeholders (Cash et al., 2003).

We add to literature that calls for connecting material and social issues (Covarrubias, 2019), opening up the nexus governance (Urbinatti et al., 2020), and co-producing knowledge through inter-and transdisciplinary approaches (Howarth and Monasterolo, 2017; Wahl et al., 2021). Differently from other, more systematic, reviews of the nexus research (e.g., Albrecht et al., 2018; Zhang et al., 2018), we present the literature in a way that explicitly aims to promote researchers' reflection and critical thinking, to foster the dialogue between academics from different scientific fields, and between academics and nonacademics, which has the production of actionable knowledge as ultimate objective.

We recognize that presenting a simple five questions does not diminish the often overwhelming complexity of nexus systems and nexus research, nor are we suggesting that this approach is itself a comprehensive nexus methodology. We also recognize 


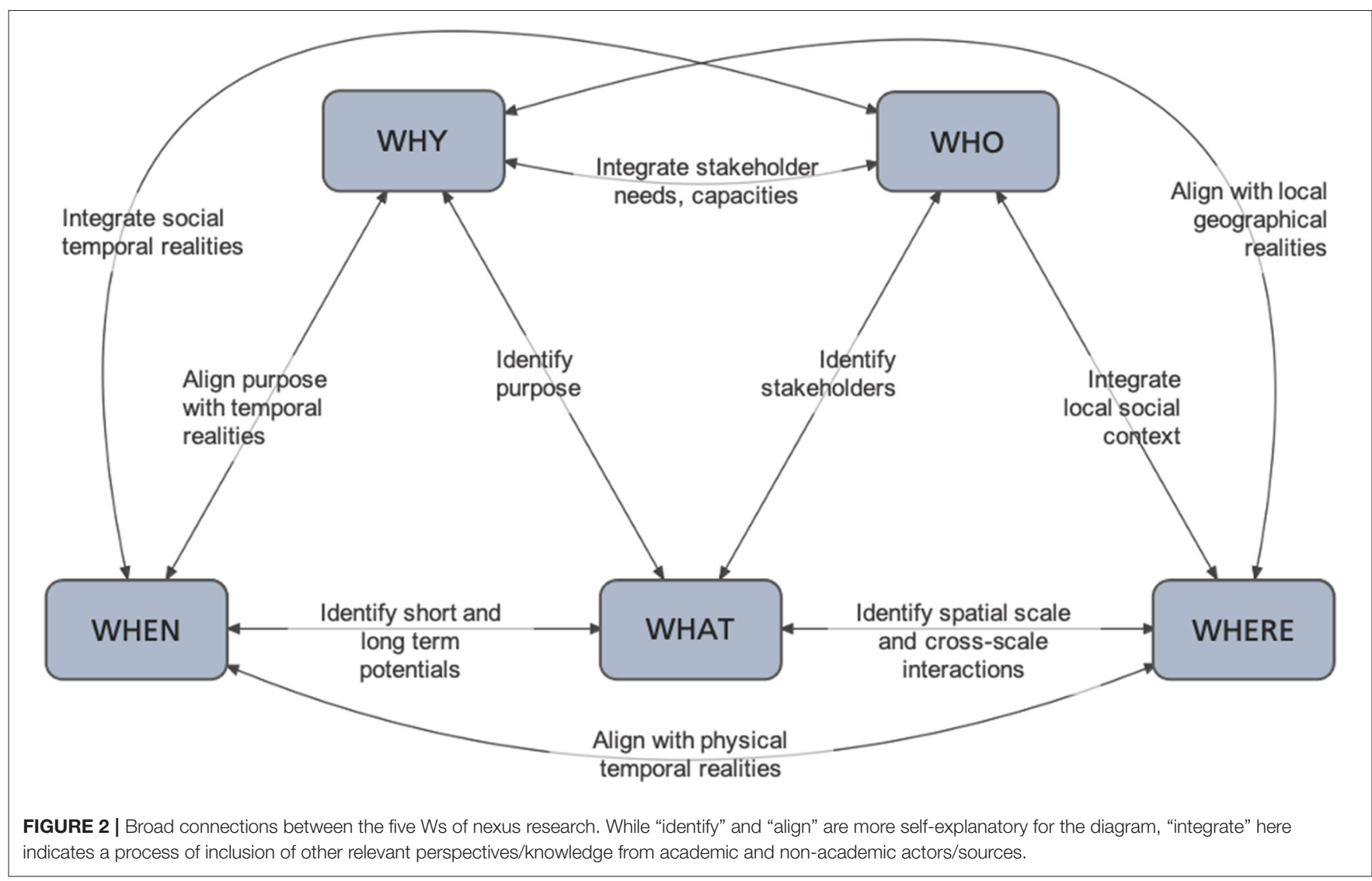

that each nexus research project may not have the scope or capacity to dive into each dimension as we have outlined here. However, as the nexus intends, we present the five Ws in order to encourage researchers to build interdisciplinary or transdisciplinary networks so purposes can be aligned and knowledge can be shared. This could mean employing mixedmethods, participatory methods, and inter- and transdisciplinary approaches (Wehrden et al., 2017). Methodological questions can also fall into the five Ws, e.g., what methods will provide the data we need, when should those methods be employed, who has experience in these methods? Therefore, we present this approach as an iterative baseline from which researchers can reflect on their decision-making and evolve WEF research as fits local sustainability needs.

\section{CONCLUSIONS}

The water-energy-food nexus first appeared with the intention of integrating sectors, bringing different actors around the same table and opening up dialogue between academic disciplines and different areas of knowledge. However, the scientific production of the last decade has specialized within the domain of technical disciplines, rather than offering a broader vision to understand problems and develop solutions. Those who approach nexus research for the first time tend to look at it through the lens of specific scientific disciplines, excluding a priori many of its nuances. With this contribution, we offer an interpretation of the literature on the nexus that is accessible, and not overly specialized, with the intention of encouraging academics and non-academics to engage in a dialogue and reflect on their decision-making in nexus research. We critically present the literature through five "W" questions, each of which addresses important points in the research that normally tend to be approached separately. Addressing "W" questions help to identify a clearer purpose for doing research on nexus, to set research boundaries, aid in identifying relevant stakeholders and shared interests, the most relevant spatial scale and cross scale interactions, and the short- or long-term research/action potentials. In each section, and particularly in the discussion, we sought to highlight how the connections apparent between the Ws further argue for taking inter- and transdisciplinary approaches, and how this grounds the research in a local context, integrating the production of scientific knowledge with relevant societal problems. With this paper, we have provided important insights that support and justify the co-production of actionable knowledge in the nexus in order to facilitate the development of sustainable solutions.

\section{AUTHOR CONTRIBUTIONS}

MD conceived the original idea of the paper and led the drafting process. MD, DW, and FM co-designed and co-wrote 
the manuscript. All co-authors reviewed, commented, and edited all sections over the various drafts of the manuscript.

\section{FUNDING}

MD, FM, TM, and GD declare that the research has been funded by FAPESP_São Paulo Research Foundation (Proc. 2018/213621; Proc. 2018/21249-0; Proc. 2017/50423-6). DW and BN declare that the research has been funded by the Swedish Energy Agency grant no. 45290-1. AO declares that the research has been funded by the Dutch research council (NWO). This research was conducted as part of the GLOCULL Project, which is part of the Sustainable Urbanisation Global Initiative (SUGI)/Food-

\section{REFERENCES}

Albrecht, T. R., Crootof, A., and Scott, C. A. (2018). The water-energy-food nexus: a systematic review of methods for nexus assessment. Environ. Res. Lett. 13:043002 doi: 10.1088/1748-9326/aaa9c6

Allain, S., Ndong, G. O., Lardy, R., and Leenhardt, D. (2018). Integrated assessment of four strategies for solving water imbalance in an agricultural landscape. Agron. Sustainable Dev. 38:60. doi: 10.1007/s13593-018-0529-z

Allouche, J., Middleton, C., and Gyawal, D. (2014). Nexus Nirvana or Nexus Nullity? A dynamic approach to security and sustainability in the water-energyfood nexus. In Nexus Nirvana or Nexus Nulity? A dynamic approach to security and sustainability in the water-energy-food nexus.

Allouche, J., Middleton, C., and Gyawali, D. (2015). Technical veil, hidden politics: interrogating the power linkages behind the nexus. Water Altern. 8, 610-26. Available online at: https://www.water-alternatives.org/index.php/ alldoc/articles/vol8/v8issue1/277-a8-1-1/file

Al-Saidi, M., and Elagib, N. A. (2017). Towards understanding the integrative approach of the water, energy and food nexus. Sci. Total Environ. 574, 1131-1139. doi: 10.1016/j.scitotenv.2016.09.046

Artioli, F., Acuto, M., and McArthur, J. (2017). The water-energy-food nexus: an integration agenda and implications for urban governance. Polit. Geogr. 61, 215-223. doi: 10.1016/j.polgeo.2017.08.009

Best, G., Van Campen, B., and Martin, D. (2000). The energy and agriculture nexus. Report Number: Environmental and Natural Resources Working Paper No. 4, UN-FAO. doi: 10.13140/RG.2.1.2041.4169

Biggs, E. M., Bruce, E., Boruff, B., Duncan, J. M. A., Horsley, J., Pauli, N., et al. (2015). Sustainable development and the water-energy-food nexus: a perspective on livelihoods. Environ. Sci. Policy 54, 389-397. doi: 10.1016/j.envsci.2015.08.002

Bijl, D. L., Bogaart, P. W., Dekker, S. C., and van Vuuren, D. P. (2018). Unpacking the nexus: different spatial scales for water, food and energy. Glob. Environ. Change 48, 22-31. doi: 10.1016/j.gloenvcha.2017.11.005

Bizikova, L., Roy, D., Swanson, D., David, H., and Mccandless, V. M. (2013). The WaterEnergy-Food Security Nexus: Towards a Practical Planning and Decision Support Framework for Landscape Investment and Risk Management International Institute for Sustainable Development (IISD). Winnipeg: International Institute for Sustainable Development (IISD).

Bleischwitz, R., Spataru, C., VanDeveer, S. D., Obersteiner, M., van der Voet, E., Johnson, C., et al. (2018). Resource nexus perspectives towards the United Nations sustainable development goals. Nature Sustain. 1, 737-743. doi: 10.1038/s41893-018-0173-2

Bréthaut, C., Gallagher, L., Dalton, J., and Allouche, J. (2019). Power dynamics and integration in the water-energy-food nexus: learning lessons for transdisciplinary research in Cambodia. Environ. Sci. Policy 94, 153-162. doi: 10.1016/j.envsci.2019.01.010

Cairns, R., and Krzywoszynska, A. (2016). Anatomy of a buzzword: the emergence of 'the water-energy-food nexus' in UK natural resource debates. Environ. Sci. Policy 64, 164-170. doi: 10.1016/j.envsci.2016. 07.007
Water-Energy established and funded by the Belmont Forum and the joint programming initiative Urban Europe. The project has received funding from the European Union's Horizon 2020 research and innovation programme under grant agreement no. 730254 .

\section{ACKNOWLEDGMENTS}

The authors thank the research team from the GLOCULL Project, practitioners and stakeholders who participated in their studies and brought significant insights for this paper. The authors also thank the reviewers for their careful reading and comments.

Cash, D. W., Adger, W. N., Berkes, F., Garden, P., Lebel, L., Olsson, P., et al. (2006). Scale and cross-scale dynamics: governance and information in a multilevel world. Ecol. Soc. 11:8. doi: 10.5751/ES-01759-110208

Cash, D. W., Clark, W. C., Alcock, F., Dickson, N. M., Eckley, N., Guston, D. H., et al. (2003). Knowledge systems for sustainable development. Proc. Nat. Acad. Sci. U.S.A. 100, 8086-8091. doi: 10.1073/pnas.1231332100

Ciegis, R., Ramanauskiene, J., and Martinkus, B. (2009). The concept of sustainable development and its use for sustainability scenarios. Eng. Econ. 62:28-37. doi: 10.5755/J01.EE.62.2.11609

Covarrubias, M. (2019). The nexus between water, energy and food in cities: towards conceptualizing socio-material interconnections. Sustain. Sci. 14, 277-287. doi: 10.1007/s11625-018-0591-0

Covarrubias, M., Spaargaren, G., and Boas, I. (2019). Network governance and the Urban Nexus of water, energy, and food: lessons from Amsterdam. Energy Sustain. Soc. 9:14. doi: 10.1186/s13705-019-0196-1

Daher, B., Saad, W., Pierce, S. A., Hülsmann, S., and Mohtar, R. H. (2017). Tradeoffs and decision support tools for FEW nexus-oriented management. Curr. Sustain. Renew. Energy Rep. 4, 153-159. doi: 10.1007/s40518-017-0075-3

Dalin, C., Wada, Y., Kastner, T., and Puma, M. J. (2017). Groundwater depletion embedded in international food trade. Nature 543, 700-704. doi: $10.1038 /$ nature21403

Dalla Fontana, M., and Boas, I. (2019). The politics of the nexus in the city of Amsterdam. Cities 95:102388. doi: 10.1016/j.cities.2019.102388

Dalla Fontana, M., Moreira, F. A., Di Giulio, G. M., and Malheiros, T. F. (2020). The water-energy-food nexus research in the Brazilian context: what are we missing? Environ. Sci. Policy 112, 172-180. doi: 10.1016/j.envsci.2020.06.021

Dargin, J., Daher, B., and Mohtar, R. H. (2019). Complexity versus simplicity in water energy food nexus (WEF) assessment tools. Sci. Total Environ. 650, 1566-1575. doi: 10.1016/j.scitotenv.2018.09.080

de Bremond, A., Preston, B. L., and Rice, J. (2014). Improving the usability of integrated assessment for adaptation practice: insights from the U.S. Southeast energy sector. Environ. Sci. Policy 42, 45-55. doi: 10.1016/j.envsci.2014.05.004

de Queiroz, A. R., Faria, V. A. D., Lima, L. M. M., and Lima, J. W. M. (2019). Hydropower revenues under the threat of climate change in Brazil. Renew. Energy 133, 873-882. doi: 10.1016/j.renene.2018.10.050

D’Odorico, P., Davis, K. F., Rosa, L., Carr, J. A., Chiarelli, D., Dell'Angelo, J., et al. (2018). The global food-energy-water nexus. Rev. Geophys. 56, 456-531. doi: 10.1029/2017RG000591

Endo, A., Burnett, K., Orencio, P. M., Kumazawa, T., Wada, C. A., Ishii, A., et al. (2015). Methods of the water-energy-food nexus. Water 7, 5806-5830. doi: 10.3390/w7105806

Endo, A., Tsurita, I., Burnett, K., and Orencio, P. M. (2017). A review of the current state of research on the water, energy, and food nexus. J. Hydrol. Reg. Stud. 11, 20-30. doi: 10.1016/j.ejrh.2015.11.010

Engström, R. E., Howells, M., and Destouni, G. (2018). Water impacts and waterclimate goal conflicts of local energy choices - notes from a Swedish perspective. Proc. Int. Assoc. Hydrol. Sci. 376, 25-33. doi: 10.5194/piahs-376-25-2018

Engström, R. E., Howells, M., Destouni, G., Bhatt, V., Bazilian, M., and Rogner, H. H. (2017). Connecting the resource nexus to basic urban service provision - 
with a focus on water-energy interactions in New York City. Sustain. Cities Soc. 31, 83-94. doi: 10.1016/j.scs.2017.02.007

Enqvist, J. P., Tengö, M., and Bodin, Ö. (2020). Are bottom-up approaches good for promoting social-ecological fit in urban landscapes? Ambio 49, 49-61. doi: 10.1007/s13280-019-01163-4

Ericksen, P. J. (2008). Conceptualizing food systems for global environmental change research. Glob. Environ. Change 18, 234-245. doi: 10.1016/j.gloenvcha.2007.09.002

Ernst, K. M., and Preston, B. L. (2017). Adaptation opportunities and constraints in coupled systems: evidence from the U.S. energy-water nexus. Environ. Sci. Policy 70, 38-45. doi: 10.1016/j.envsci.2017.01.001

Falkenmark, M., Rockstrom, J., and Rockström, J. (2004). Balancing Water for Humans and Nature. The New Approach in Ecohydrology. Earthscan.

FAO. (2013). Climate-smart agriculture sourcebook. In: Sourcebook on ClimateSmart Agriculture, Forestry and Fisheries.

Garcia, D. J., and You, F. (2016). The water-energy-food nexus and process systems engineering: a new focus. Comput. Chem. Eng. 91, 49-67. doi: 10.1016/j.compchemeng.2016.03.003

Ghodsvali, M., Krishnamurthy, S., and de Vries, B. (2019). Review of transdisciplinary approaches to food-water-energy nexus: a guide towards sustainable development. Environ. Sci. Policy 101, 266-278. doi: 10.1016/j.envsci.2019.09.003

Giatti, L. L., Urbinatti, A. M., Carvalho, C. M., Bedran-Martins, A. M., Santos, I. P. O., Honda, S. O., et al. (2019). Nexus of exclusion and challenges for sustainability and health in an urban periphery in Brazil. Cad. Saúde. Pública 35:e0007918. doi: 10.1590/0102-311x00007918

Guillaume, J. H. A., Kummu, M., Eisner, S., and Varis, O. (2015). Transferable principles for managing the nexus: lessons from historical global water modelling of Central Asia. Water 7, 4200-4231. doi: 10.3390/w7084200

Hake, J.-F., Schlör, H., Schürmann, K., and Venghaus, S. (2016). Ethics, sustainability and the water, energy, food nexus approach - a new integrated assessment of urban systems. Energy Procedia 88, 236-242. doi: 10.1016/j.egypro.2016.06.155

Hamiche, A. M., Stambouli, A. B., and Flazi, S. (2016). A review of the water-energy nexus. Renew. Sustain. Energy Rev. 65, 319-331. doi: 10.1016/j.rser.2016.07.020

Hansson, S., and Polk, M. (2018). Assessing the impact of transdisciplinary research: the usefulness of relevance, credibility, and legitimacy for understanding the link between process and impact. Res. Eval. 27, 132-144. doi: 10.1093/reseval/rvy004

Hoekstra, A. Y., Chapagain, A. K., Mekonnen, M. M., and Aldaya, M. M. (2011). The Water Footprint Assessment Manual: Setting the Global Standard. Earthscan, London: Routledge.

Hoff, H. (2011). Understanding the Nexus. Background paper for the Bonn2011 Nexus Conference: Stockholm Environment Institute.

Hoff, and Kasparek. (2016). The Water-Energy-Food Security Nexus-Analysis of the Project Portfolio and Assessment of Opportunities for Nexus Mainstreaming. Deutsche Gesellschaft Für Internationale Zusammenarbeit (GIZ), Bonn.

Hoolohan, C., Larkin, A., McLachlan, C., Falconer, R., Soutar, I., Suckling, J., et al. (2018). Engaging stakeholders in research to address waterenergy-food (WEF) nexus challenges. Sustain. Sci. 13, 1415-1426. doi: 10.1007/s11625-018-0552-7

Howarth, C., and Monasterolo, I. (2016). Understanding barriers to decision making in the UK energy-food-water nexus: the added value of interdisciplinary approaches. Environ. Sci. Policy 61, 53-60. doi: 10.1016/j.envsci.2016.03.014

Howarth, C., and Monasterolo, I. (2017). Opportunities for knowledge coproduction across the energy-food-water nexus: making interdisciplinary approaches work for better climate decision making. Environ. Sci. Policy 75, 103-110. doi: 10.1016/j.envsci.2017.05.019

IEA. (2016). World Energy Outlook 2016. Available online at: https://www.iea.org/ reports/world-energy-outlook-2016

Jasanoff, S. (2005). Technologies of Humility: Citizen Participation in Governing Science. In: Bogner A, Torgersen H, editors. Wozu Experten? Ambivalenzen der Beziehung von Wissenschaft und Politik. VS Verlag für Sozialwissenschaften, 370-389. doi: 10.1007/978-3-322-80692-5_17

Kenway, S. J., Lant, P. A., Priestley, A., and Daniels, P. (2011). The connection between water and energy in cities: a review. Water Sci. Technol. 63, 1983-1990. doi: $10.2166 /$ wst. 2011.070
Khan, Z., Linares, P., Rutten, M., Parkinson, S., Johnson, N., and GarcíaGonzález, J. (2018). Spatial and temporal synchronization of water and energy systems: towards a single integrated optimization model for long-term resource planning. Appl. Energy 210, 499-517. doi: 10.1016/j.apenergy.2017.05.003

Kibler, K. M., Reinhart, D., Hawkins, C., Motlagh, A. M., and Wright, J. (2018). Food waste and the food-energy-water nexus: a review of food waste management alternatives. Waste Manag. 74, 52-62. doi: 10.1016/j.wasman.2018.01.014

King, C. W., and Carbajales-Dale, M. (2016). Food-energy-water metrics across scales: project to system level. J. Environ. Stud. Sci. 6, 39-49. doi: 10.1007/s13412-016-0390-9

Kirby, R. M., Bartram, J., and Carr, R. (2003). Water in food production and processing: quantity and quality concerns. Food Control 14, 283-299. doi: 10.1016/S0956-7135(02)00090-7

Kurian, M. (2017). The water-energy-food nexus: trade-offs, thresholds and transdisciplinary approaches to sustainable development. Environ. Sci. Policy 68, 97-106. doi: 10.1016/j.envsci.2016.11.006

Lant, C., Baggio, J., Konar, M., Mejia, A., Ruddell, B., Rushforth, R., et al. (2019). The U.S. food-energy-water system: a blueprint to fill the mesoscale gap for science and decision-making. Ambio 48, 251-263. doi: 10.1007/s13280-018-1077-0

Leck, H., Conway, D., Bradshaw, M., and Rees, J. (2015). Tracing the water-energyfood nexus: description, theory and practice. Geogr. Compass 9, 445-460. doi: 10.1111 /gec 3.12222

Liu, J., Hull, V., Batistella, M., DeFries, R., Dietz, T., Fu, F., et al. (2013). Framing sustainability in a telecoupled world. Ecol. Soc. 18:26. doi: 10.5751/ES-05873-180226

Liu, J., Hull, V., Godfray, H. C. J., Tilman, D., Gleick, P., Hoff, H., et al. (2018). Nexus approaches to global sustainable development. Nat. Sustain. 1, 466-476. doi: 10.1038/s41893-018-0135-8

Liu, J., Mooney, H., Hull, V., Davis, S. J., Gaskell, J., Hertel, T., et al. (2015). Systems integration for global sustainability. Science 347:6225. doi: $10.1126 /$ science. 1258832

Magliocca, N. R. (2020). Agent-based modeling for integrating human behavior into the food-energy-water nexus. Land 9:519. doi: 10.3390/land9120519

Meadows, D. (1999). Leverage Points: Places to Intervene in a System. Hartland: The Sustainability Institute, 18.

Medeiros, D. L., Queiroz, L. M., Cohim, E., de Almeida-Neto, J. A., and Kiperstok, A. (2020). Human urine fertiliser in the Brazilian semi-arid: environmental assessment and water-energy-nutrient nexus. Sci. Total Environ. 713:136145. doi: 10.1016/j.scitotenv.2019.136145

Mekonnen, M. M., and Hoekstra, A. Y. (2010). The green, blue and grey water footprint of farm animals and animal products. Hydrol. Earth Syst. Sci. Discussions 2:123. doi: 10.5194/hessd-8-763-2011

Mguni, P., van Vliet, B., Spaargaren, G., Nakirya, D., Osuret, J., Isunju, J. B., et al. (2020). What could go wrong with cooking? Exploring vulnerability at the water, energy and food Nexus in Kampala through a social practices lens. Glob. Environ. Change 63:102086. doi: 10.1016/j.gloenvcha.2020.102086

Middleton, C., Allouche, J., Gyawali, D., and Allen, S. (2015). The rise and implications of the water-energy-food nexus in southeast asia through an environmental justice lens. Water Altern. 8:28. Available online at: https://www. water-alternatives.org/index.php/all-abs/269-a8-1-2/file

Mitchell, R. K., Agle, B. R., and Wood, D. J. (1997). Toward a theory of stakeholder identification and salience: defining the principle of who and what really counts. Acad. Manag. Rev. 22, 853-886. doi: 10.5465/amr.1997.97110 22105

Monforti, F., Dallemand, J., Pinedo Pascua, I., Motola, V., Banja, M., Scarlat, N., et al. (2015). Energy Use in the EU Food Sector: State of Play and Opportunities for Improvement. Luxembourg: Publications Office of the European Union. doi: $10.2790 / 158316$

Newell, J. P., Goldstein, B., and Foster, A. (2019). A 40-year review of food-energywater nexus literature and its application to the urban scale. Environ. Res. Lett. 14:073003. doi: 10.1088/1748-9326/ab0767

Pahl-Wostl, C. (2019). Governance of the water-energy-food security nexus: a multi-level coordination challenge. Environ. Sci. Policy 92, 356-367. doi: 10.1016/j.envsci.2017.07.017

Paim, M.-A., Dalmarco, A. R., Yang, C.-H., Salas, P., Lindner, S., Mercure, J.-F., et al. (2019). Evaluating regulatory strategies for mitigating hydrological risk in 
Brazil through diversification of its electricity mix. Energy Policy 128, 393-401. doi: 10.1016/j.enpol.2018.12.064

Pellegrini, P., and Fernández, R. J. (2018). Crop intensification, land use, and onfarm energy-use efficiency during the worldwide spread of the green revolution. Proc. Nat. Acad. Sci. U.S.A. 115, 2335-2340. doi: 10.1073/pnas.1717072115

Petljak, K., Zulauf, K., Štulec, I., Seuring, S., and Wagner, R. (2018). Green supply chain management in food retailing: survey-based evidence in Croatia. Supply Chain Manag. 23, 1-15. doi: 10.1108/SCM-04-2017-0133

Preston, B. L. (2013). Local path dependence of U.S. socioeconomic exposure to climate extremes and the vulnerability commitment. Glob. Environ. Change 23, 719-732. doi: 10.1016/j.gloenvcha.2013.02.009

Ramaswami, A., Boyer, D., Nagpure, A. S., Fang, A., Bogra, S., Bakshi, B., et al. (2017). An urban systems framework to assess the trans-boundary food-energywater nexus: implementation in Delhi, India. Environ. Res. Lett. 12:025008. doi: $10.1088 / 1748-9326 /$ aa5556

Rasul, G. (2016). Managing the food, water, and energy nexus for achieving the sustainable development goals in South Asia. Environ. Dev. 18, 14-25. doi: 10.1016/j.envdev.2015.12.001

Rasul, G., and Sharma, B. (2016). The nexus approach to water-energy-food security: an option for adaptation to climate change. Clim. Policy 16, 682-702. doi: 10.1080/14693062.2015.1029865

Raworth, K. (2017). Doughnut Economics: Seven Ways to Think Like a 21st-Century Economist. Chelsea Green Publishing.

Rulli, M. C., Bellomi, D., Cazzoli, A., De Carolis, G., and D’Odorico, P. (2016). The water-land-food nexus of first-generation biofuels. Sci. Rep. 6:22521. doi: 10.1038/srep22521

Sanjuan-Delmás, D., Llorach-Massana, P., Nadal, A., Ercilla-Montserrat, M., Muñoz, P., Montero, J. I., et al. (2018). Environmental assessment of an integrated rooftop greenhouse for food production in cities. J. Clean. Prod. 177, 326-337. doi: 10.1016/j.jclepro.2017.12.147

Schlör, H., Venghaus, S., Fischer, W., Märker, C., and Hake, J.-F. (2018). Deliberations about a perfect storm - The meaning of justice for food energy water-nexus (FEW-Nexus). J. Environ. Manage. 220, 16-29. doi: 10.1016/j.jenvman.2018.04.097

Sharma, P., and Kumar, S. N. (2020). The global governance of water, energy, and food nexus: allocation and access for competing demands. Int. Environ. Agreements Polit. Law Econ. 20, 377-391. doi: 10.1007/s10784-020-09488-2

Simpson, G. B., and Jewitt, G. P. (2019a). The water-energy-food nexus in the anthropocene: Moving from 'nexus thinking' to 'nexus action.' Curr. Opin. Environ. Sustain. 40, 117-123. doi: 10.1016/j.cosust.2019.10.007

Simpson, G. B., and Jewitt, G. P. W. (2019b). The development of the water-energyfood nexus as a framework for achieving resource security: a review. Front. Environ. Sci. 7:8. doi: 10.3389/fenvs.2019.00008

Stoessel, F., Juraske, R., Pfister, S., and Hellweg, S. (2012). Life cycle inventory and carbon and water foodprint of fruits and vegetables: application to a swiss retailer. Environ. Sci. Technol. 46, 3253-62. doi: 10.1021/es20 30577

Taniguchi, M., Burnett, K. M., Shimada, J., Hosono, T., Wada, C. A., and Ide, K. (2019). Recovery of lost nexus synergy via payment for environmental services in Kumamoto, Japan. Front. Environ. Sci. 7:28. doi: 10.3389/fenvs.2019. 00028

Tengö, M., and Andersson, E. (2021). Solutions-oriented research for sustainability: turning knowledge into action. 50th Anniversary Collection: Solutions-oriented Research. Ambio 50. doi: 10.1007/s13280-02001492-9

Turnhout, E., Metze, T., Wyborn, C., Klenk, N., and Louder, E. (2020). The politics of co-production: participation, power, and transformation. Curr. Opin. Environ. Sustain. 42, 15-21. doi: 10.1016/j.cosust.2019.11.009

Urbinatti, A. M., Dalla Fontana, M., Stirling, A., and Giatti, L. L. (2020). 'Opening up' the governance of water-energy-food nexus: towards a sciencepolicy-society interface based on hybridity and humility. Sci. Total Environ. 744:140945. doi: 10.1016/j.scitotenv.2020.140945

Vanham, D., Leip, A., Galli, A., Kastner, T., Bruckner, M., Uwizeye, A., et al. (2019). Environmental footprint family to address local to planetary sustainability and deliver on the SDGs. Sci. Total Environ. 693:133642. doi: 10.1016/j.scitotenv.2019.133642
Venghaus, S., and Hake, J.-F. (2018). Nexus thinking in current EU policies-the interdependencies among food, energy and water resources. Environ. Sci. Policy 90, 183-192. doi: 10.1016/j.envsci.2017.12.014

Villarroel Walker, R., Beck, M. B., Hall, J. W., Dawson, R. J., and Heidrich, O. (2017). Identifying key technology and policy strategies for sustainable cities: a case study of London. Environ. Dev. 21, 1-18. doi: 10.1016/j.envdev.2016.11.006

Wa'el, A., H., Memon, F. A., and Savic, D. A. (2017). An integrated model to evaluate water-energy-food nexus at a household scale. Environ. Model. Softw. 93, 366-380. doi: 10.1016/j.envsoft.2017.03.034

Wahl, D., Ness, B., and Wamsler, C. (2021). Implementing the urban foodwater-energy nexus through urban laboratories: a systematic literature review. Sustain. Sci. 16, 663-676. doi: 10.1007/s11625-020-00893-9

Walker, C. (2020). Nexus thinking and the geographies of children, youth and families: towards an integrated research agenda. Child. Geogr. 18, 351-363. doi: 10.1080/14733285.2019.1642449

Wehrden, H., von, Luederitz, C., Leventon, J., and Russell, S. (2017). Methodological challenges in sustainability science: a call for method plurality, procedural rigor and longitudinal research. Chall. Sustain. 5, 35-42. doi: 10.12924/cis2017.05010035

Wichelns, D. (2017). The water-energy-food nexus: is the increasing attention warranted, from either a research or policy perspective? Environ. Sci. Policy 69, 113-123. doi: 10.1016/j.envsci.2016.12.018

Wiegleb, V., and Bruns, A. (2018). What is driving the water-energy-food nexus? Discourses, knowledge, and politics of an emerging resource governance concept. Front. Environ. Sci. 6:128. doi: 10.3389/fenvs.2018.00128

Williams, J., Bouzarovski, S., and Swyngedouw, E. (2014). Politicising the Nexus: Nexus Technologies, Urban Circulation, and the Coproduction of Water-Energy. Nexus Network Think Piece Series Paper 001. Available online at: https:// thenexusnetwork.org/wp-content/uploads/2014/11/Williams-BouzarovskiSwyngedouw-Politicising-the-nexus-Nexus-Thinkpiece-2014.pdf.

Winemiller, K. O., McIntyre, P. B., Castello, L., Fluet-Chouinard, E., Giarrizzo, T., Nam, S., et al. (2016). Balancing hydropower and biodiversity in the Amazon, Congo, and Mekong. Science 351, 128-129. doi: 10.1126/science.aa c7082

Yuan, M.-H., Chiueh, P.-T., and Lo, S.-L. (2021). Measuring urban food-energywater nexus sustainability: finding solutions for cities. Sci. Total Environ. 752:141954. doi: 10.1016/j.scitotenv.2020.141954

Zhang, C., Chen, X., Li, Y., Ding, W., and Fu, G. (2018). Water-energy-food nexus: concepts, questions and methodologies. J. Cleaner Prod. 195, 625-639. doi: $10.1016 /$ j.jclepro.2018.05.194

Zhang, X., and Vesselinov, V. V. (2017). Integrated modeling approach for optimal management of water, energy and food security nexus. Adv. Water Resour. 101, 1-10. doi: 10.1016/j.advwatres.2016.12.017

Zhu, J., Kang, S., Zhao, W., Li, Q., Xie, X., and Hu, X. (2020). A bibliometric analysis of food-energy-water nexus: progress and prospects. Land 9:504. doi: 10.3390/land9120504

Conflict of Interest: The authors declare that the research was conducted in the absence of any commercial or financial relationships that could be construed as a potential conflict of interest.

Publisher's Note: All claims expressed in this article are solely those of the authors and do not necessarily represent those of their affiliated organizations, or those of the publisher, the editors and the reviewers. Any product that may be evaluated in this article, or claim that may be made by its manufacturer, is not guaranteed or endorsed by the publisher.

Copyright (๑) 2021 Dalla Fontana, Wahl, Moreira, Offermans, Ness, Malheiros and Di Giulio. This is an open-access article distributed under the terms of the Creative Commons Attribution License (CC BY). The use, distribution or reproduction in other forums is permitted, provided the original author(s) and the copyright owner(s) are credited and that the original publication in this journal is cited, in accordance with accepted academic practice. No use, distribution or reproduction is permitted which does not comply with these terms. 